\title{
Važnost provođenja randomiziranih kliničkih istraživanja
}

\section{Importance of conducting randomised clinical trials}

\author{
Davor Štimac $^{1 *}$, Alojzije Lacković2 ${ }^{2}$ Goran Poropat ${ }^{1}$
}

${ }^{1}$ Zavod za gastroenterologiju, Klinika za internu medicinu, Klinički bolnički centar Rijeka, Rijeka

${ }^{2}$ Medicinski fakultet Sveučilišta u Rijeci, Rijeka
Sažetak. Kliničko ispitivanje (pokus ili studija) smatra se jedinim znanstvenim dokazom djelotvornosti nekog lijeka, terapijskog ili kirurškog zahvata. U posljednjih 50 godina dominantan oblik istraživanja u medicinskoj znanosti postala su randomizirana klinička istraživanja (engl. Randomised clinical trials; RCT) te danas predstavljaju kamen temeljac medicine temeljene na dokazima (engl. Evidence based medicine; EBM) Riječ je o kvantitativno komparativnom obliku istraživanja pomoću kojeg se uspoređuje učinak dvaju ili više postupaka na ispitanike koji su nasumično podijeljeni u više istraživačkih skupina. Stupanj dokaza, dobivenih pomoću randomiziranih kliničkih istraživanja, predstavlja najviši stupanj dokaza u medicinskoj znanosti, a smjernice koje predstavljaju sistematizirane principe liječenja uglavnom se temelje na najboljim dostupnim podacima iz kliničkih istraživanja. Smjernice omogućuju liječnicima da uz pomoć svog iskustva i znanja, vodeći pritom računa o osobitostima i stavovima pacijenata, najbolje liječe pacijente. Pouzdanost $i$ kvaliteta rezultata RCT-a ovise o određenim karakteristikama samog istraživanja, poput adekvatno provedenog postupka randomizacije, "zaslijepljenosti" istraživača i ispitanika, te pravilno oblikovanog protokola istraživanja. Usprkos velikom broju prednosti, postoje i određene negativne karakteristike randomiziranih kliničkih istraživanja, poput etičkih pitanja opravdanosti istraživanja, cijene, nemogućnosti provedbe samog istraživanja te nedovoljno dobre informiranosti pacijenata o važnosti njihova provođenja, kako za medicinsku znanost, tako i za njih same.

Ključne riječi: medicina temeljena na dokazima; randomizacija; zaslijepljenost

Abstract. Clinical trial (experiment or study) is considered to be the only scientific evidence of the efficiency of a drug, therapeutic or surgical procedure. In the last 50 years, randomized clinical trials (RCTs) have become the dominant form of research in medical science and today represent the base of Evidence Based Medicine (EBM). RCTs are quantitative, comparative and controlled experiments in which the effect of two or more clinical procedures is compared on subjects randomly divided into several research groups. The level of evidence, obtained through randomized clinical trials, represents the highest level of evidence in medical science. The guidelines that represent systematized principles of medical treatment are mainly based on the best available clinical data. The guidelines allow physicians, along with their own experience and knowledge to provide the best available treatment for their patients taking care of their personality and characters. The quality of RCT results depends on certain characteristics of the research itself, such as the adequately conducted randomization procedure, the "blindness" of researchers and subjects and properly designed research protocol. Despite the great number of advantages, there are certain negative characteristics of randomized clinical trials, such as ethical questions of justification of the research, price of the research, impossibility to carry out the research itself, and inadequate knowledge of patients about the importance of their implementation, both for medical science and them.

Key words: blinding; evidence-based medicine; randomisation

http://hrcak.srce.hr/medicina 


\section{UVOD}

U današnje doba svjedoci smo pojave sve većeg broja lijekova na tržištu, te se čini važnijim no ikada unaprijediti postupke i metode za utvrđivanje njihove djelotvornosti i sigurnosti. Upravo stoga se posljednjih desetljeća razvio novi pravac u medicini koji se naziva Evidence based medicine (EBM), odnosno medicina temeljena na dokazima. Još je Sir William Osler, jedan od osnivača moderne medicine, prije dva stoljeća izjavio: "Medicina je umjetnost temeljena na znanosti., ${ }^{1}$ Glavna zadaća EBM-a jest ispitati djelotvornost svakog novog $\mathrm{i}$ postojećeg lijeka, terapijskog postupka ili kirurškog zahvata, te na temelju rezultata istraživanja odlučiti koji je od njih adekvatan za pacijente ${ }^{2}$. Kamen temeljac EBM-a danas su randomizirana klinička istraživanja (engl. randomised clinical trials; RCT) ${ }^{3}$. Randomizirana klinička istraživanja su kvantitativno-komparativni oblik istraživanja pomoću kojeg se uspoređuje učinak dvaju ili više postupaka na ispitanike, koji su nasumično podijeljeni u više istraživačkih skupina ${ }^{4}$. Ono što randomizirana klinička istraživanja čini posebnim te ih razlikuje od ostalih načina istraživanja jest upravo metoda randomizacije, kojom se nastoji postići potpuna vjerodostojnost dobivenih rezultata.

\section{RANDOMIZIRANA KLINIČKA ISTRAŽIVANJA}

Kliničko ispitivanje (pokus ili studija) smatra se jedinim znanstvenim dokazom djelotvornosti nekog lijeka, terapijskog ili kirurškog zahvata ${ }^{5}$. Kako je s vremenom značajno narastao broj lijekova koji se koriste u kliničkoj praksi, tako je danas za liječenje jedne bolesti, stanja ili simptoma na raspolaganju više lijekova. U svrhu određivanja optimalnog lijeka ili terapijskog postupka koriste se upravo rezultati kliničkih ispitivanja. Pravila EBMa kažu da rezultati kliničkog istraživanja, koje se smatra vjerodostojnim, moraju biti provedeni i prikupljeni uz ispunjavane određenih uvjeta ${ }^{5}$. Prvi od tih uvjeta jest randomizacija. Randomizacija je postupak koji osigurava da svaki pacijent koji se uključi u kliničko ispitivanje ima jednaku vjerojatnost da bude razvrstan u skupinu koja prima ispitivani lijek, odnosno eksperimentalnu skupinu ili u kontrolnu skupinu koja prima lijek usporedbe, a ponekad i placebo ${ }^{5}$. Pacijenti se randomiziraju slučajnim odabirom, najčešće pomoću računalnih programa, metodama poput bacanja kocke ili izvlačenja papirića ${ }^{6}$. Isto se tako procesom randomizacije postiže jednolika raspodjela karakteristika ispitanika po skupinama. Na taj se način unutar ispitivanih skupina nalaze ljudi različitih poznatih karakteristika, poput dobi, spola, rase, komorbiditeta, izloženosti okolišnim čimbenicima, ali i nevidljivih faktora, poput genetskih faktora. Valja naglasiti da se randomizacijom ne postiže samo ravnopravna raspodjela ispitanika po skupinama, već i ispitivane skupine imaju karakteristike koje su

Randomizirana klinička istraživanja predstavljaju osnovu današnje medicine temeljene na dokazima.

najsličnije općoj populaciji. Osim jednostavne randomizacije, još se dva oblika randomizacije provode u kliničkim istraživanjima. Prvi od njih je restriktivna randomizacija, kojom se izjednačava broj ispitanika u svakoj od skupina ${ }^{4}$. Ispitanici se podijele u manje blokove koji sadrže određen broj nasumično odabranih ispitanika iz kontrolne te intervencijske skupine ${ }^{4}$. Drugi oblik dodatne randomizacije jest stratificirana randomizacija ${ }^{4}$. Stratificiranom randomizacijom se određene poznate karakteristike ispitanika, poput, primjerice, dobi ili tjelesne težine, jednoliko raspodjeljuju unutar istraživačkih skupina. Kako bi se postigla stratificirana randomizacija, istraživači najprije moraju identificirati karakteristike ispitanika koje bi mogle utjecati na ishod rezultata istraživanja te nakon toga stvoriti zasebnu shemu pomoću koje će postići jednoliku raspodjelu tih karakteristika po skupinama ${ }^{4}$. Postupkom randomizacije utjecaj liječnika, odnosno izvršitelja pokusa, na krajnje rezultate istraživanja sveden je na minimum, omogućujući na taj način veću vjerodostojnost rezultata ${ }^{6}$. Druga važna karakteristika randomiziranih kliničkih istraživanja, koja uvelike pridonosi pouzdanosti njihovih rezultata, jest "zaslijepljenost" pacijenta i ispitivača. Pod pojmom "zaslijepljenost" podrazumijeva se provođenje kliničkih istraživanje u obliku jednostruko ili višestruko slijepih pokusa. $U$ jednostruko slijepom pokusu ispitanik zna koja skupina ispitanika prima ispitivani lijek, a koja skupina prima placebo ili lijek usporedbe. Na taj način ispitanik može svojim subjek- 
tivnim stavom i uplitanjem prilikom izvođenja istraživanja uvelike utjecati na krajnji ishod rezultata. Zbog toga se većina randomiziranih kliničkih istraživanja provodi u obliku dvostruko ili čak i trostruko slijepih pokusa. U dvostruko slijepome pokusu ispitanik i ispitanici su "zaslijepljeni", a jedino je supervizor istraživanja upoznat sa svim detaljima istraživanja, dok su u trostruko slijepome pokusu dodatno "zaslijepljene" i osobe koje analiziraju rezultate istraživanja, evidentiraju ishode ili pišu članak. Dizajn i protokol samog

Randomizacija je postupak koji osigurava da svaki pacijent uključen $u$ istraživanje ima jednaku vjerojatnost svrstavanja u eksperimentalnu, odnosno kontrolnu skupinu.

istraživanja također pripadaju izrazito važnim karakteristikama randomiziranih kliničkih istraživanja te pridonose njihovoj kvaliteti. Svako istraživanje započinje definiranjem ciljeva istraživanja, koji se mogu podijeliti na primarne i sekundarne ciljeve ${ }^{7}$. U slučaju postavljanja velikog broja primarnih ciljeva istraživanja kvaliteta istraživanja se smanjuje jer je fokus ispitivača raspršen na previše zadataka koje moraju ispuniti, te takva istraživanja najčešće nemaju definitivni zaključak ${ }^{7}$. To je razlog zašto bi idealna istraživanja trebala imati samo jedan primarni cilj na koji će istraživači usmjeriti cijelu svoju pozornost i na koji će u zaključku, na temelju rezultata istraživanja, dati pouzdan odgovor ${ }^{7}$. Nakon cilja istraživanja slijedi postavljanje hipoteze u kojoj se prejudicira ishod istraživanja. Hipoteza može imati tri oblika: ekvivalentni, superiorni te neinferiorni oblik ${ }^{8}$. Ekvivalentna hipoteza podrazumijeva da je učinkovitost novoispitivanog postupka jednaka učinkovitosti uspoređenog postupka. Kod superiorne hipoteze, novoispitivani postupak ima veću učinkovitost od postupka usporedbe, dok kod neinferiorne hipoteze novoistraživani postupak ima jednaku učinkovitost poput usporednog postupka, no neke su druge karakteristike, poput cijene, načina primjene, nuspojava ili duljine primjene, povoljnije negoli kod postupka usporedbe ${ }^{8}$. Nakon postavljene hipoteze slijedi samo istraživanje koje rezultira određenim rezultatima. Rezultati se obrađuju te istraživači na temelju tih rezultata donose zaključke istraživanja koji mogu potvrditi ili negirati ranije postavljenu hipotezu ${ }^{8}$. Još jedna važna karakteristika randomiziranih kliničkih istraživanje jest dovoljno dugo i pažljivo praćenje pacijenata ${ }^{3}$. Riječ je o istraživanjima koja traju nekoliko godina te samim time zahtijevaju dugotrajno i pažljivo praćenje pacijenata, kako bi se i najmanje razlike između skupina ispitanika primijetile te zabilježile. Randomizirana klinička istraživanja u idealnim uvjetima ne bi trebala trajati duže od dvije godine jer u suprotnom istraživanje može postati zastarjelo i irelevantno s obzirom na dinamiku pojavljivanja novih terapijskih postupaka te istraživanja u medicini?.

VAŽNOST RANDOMIZIRANIH KLINIČKIH ISTRAŽIVANJA

Jedan od glavnih uzroka ubrzanog napretka medicinske znanosti u posljednjih 50 godina jest razvoj randomiziranih kliničkih istraživanja ${ }^{4}$. U svakodnevnoj liječničkoj praksi dnevna potreba za relevantnim i valjanim informacijama o dijagnozi, liječenju i prevenciji javlja se u prosjeku pet puta za hospitaliziranoga i dva puta za svakog trećeg ambulantnog pacijenta ${ }^{5}$. Nažalost, tradicionalni izvori informacija ne zadovoljavaju spomenute potrebe, udžbenici su zastarjeli, časopisi su suviše detaljni, a stručna mišljenja pojedinaca nedovoljno pouzdana. Isto je tako vrijeme koje je na raspolaganju u svakodnevnom kliničkom radu nedovoljno da bi se pronašli i usvojili podaci i dokazi o vrijednosti nekog dijagnostičkog testa, terapijskog ili preventivnog postupka. Zbog navedenih poteškoća u kliničkoj medicini koriste se smjernice koje predstavljaju sistematizirane principe liječenja, a uglavnom se temelje na najboljim dostupnim podacima iz kliničkih istraživanja ${ }^{5}$. Smjernice omogućuju liječnicima da uz pomoć svog iskustva i znanja, pazeći pritom na osobitosti i stavove pacijenata, najbolje liječe pacijenta. Prilikom sastavljanja smjernica koriste se podaci i dokazi različitih vrijednosti ${ }^{5}$. Vrijednost dokaza kategorizira se od jedan do četiri, a prema vrijednosti dokaza određuje se snaga preporuke. Kolika je zapravo važnost randomiziranih kliničkih istraživanja najbolje pokazuje podatak da su dva najviša stupnja kategorizacije dokaza, prema klasifikaciji AHCPR (engl. Agency for Health Care Policy and Research) dokazi dobiveni postupkom metaanaliza randomizira- 
nih kontroliranih pokusa (dokaz stupnja la) ili dokazi dobiveni najmanje jednim randomiziranim kontroliranim pokusom (dokaz stupnja lb). Isto tako najviši stupanj preporuke, odnosno čvrsta preporuka, temelji se na dokazu kategorije prvog stupnja, odnosno dokazima dobivenima randomiziranim kliničkim istraživanjima (slika 1$)^{9}$. lako su randomizirana klinička istraživanja postojala i ranije, njihova važnost spoznata je tek na kraju dvadesetog stoljeća ${ }^{10}$. Tada je jedno randomizirano kliničko istraživanje iz 1987. godine u SAD-u promijenilo gledište medicinske struke na važnost provođenja kliničkih istraživanja te razvoja medicine temeljene na dokazima kao sastavnog dijela moderne medicine. Primarni cilj toga istraživanja bio je dokazati na koji način upotreba antiaritmičkih lijekova (flekainid i enkainid) kod osoba s pojavom ventrikularnih aritmija utječe na preživljenje pacijenata ${ }^{11}$. Za vrijeme istraživanja ispitanici su procesom randomizacije bili podijeljeni u dvije skupine, od kojih je jedna primala tadašnju standardnu antiaritmičku terapiju, dok je druga skupina primala placebo $^{11}$. Nakon dvogodišnjeg istraživanja ustanovljeno je da je grupa koja je primala placebo imala čak 2,64 puta manju smrtnost ${ }^{11}$. Posljedica istraživanja bila je mijenjanje smjernica u načinu liječenja ventrikularnih aritmija. Jednu godinu nakon završetka istraživanja, odnosno 1990. godine, FDA (engl. Food and Drug Administration) u SAD-u proglašava randomizirana klinička istraživanja obveznim načinom ispitivanja učinkovitosti i sigurnosti novih lijekova koji se plasiraju na tržište ${ }^{10}$. Osim novih lijekova, randomizirana klinička istraživanja počela su se koristiti i za procjenu svih dotadašnjih standardnih oblika liječenja, što je rezultiralo velikim pomakom prema dokazano najboljim oblicima liječenja pacijenata. Isto tako, uvođenje randomiziranih kliničkih istraživanja u medicinsku praksu omogućilo je liječnicima diljem svijeta da budu pravovremeno informirani i najpreciznije upoznati s bilo kakvim novitetima u medicini.

PREDNOSTI I NEDOSTATCI RANDOMIZIRANIH KLINIČKIH ISTRAŽIVANJA

Jedna od najvećih prednosti randomiziranih kliničkih istraživanja, kao što je već ranije navedeno, jest pouzdanost i objektivnost rezultata. Objektivnost se temelji prvenstveno na dvjema karakteristika-

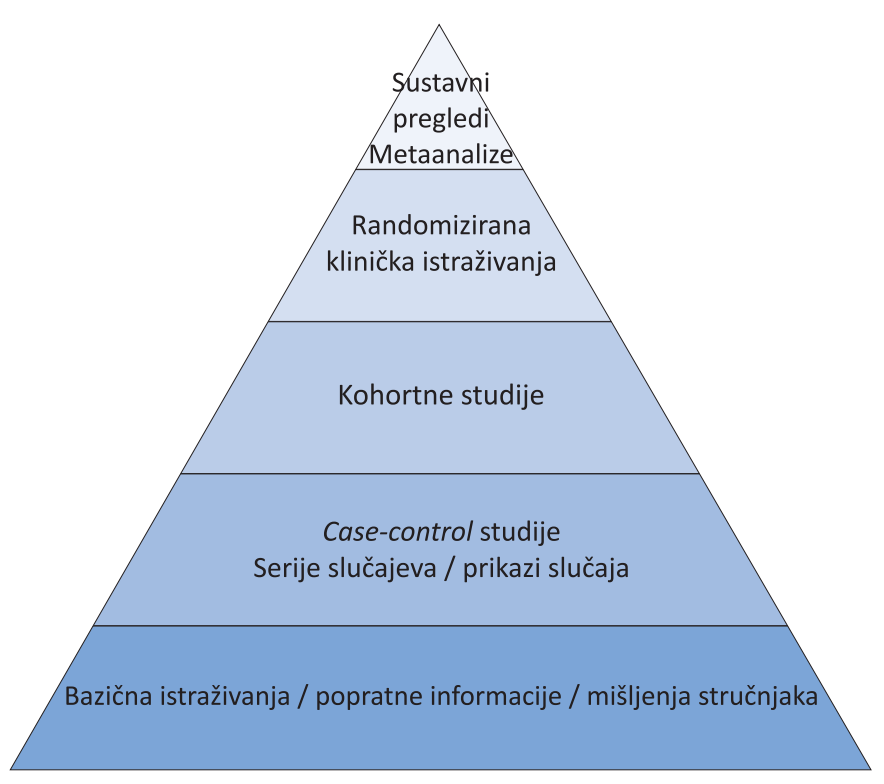

Slika 1. Piramida razine dokaza u medicini temeljenoj na dokazima (prilagođeno prema ref. 9)

ma, a to su randomizacija i "zaslijepljenost". Tim je dvjema karakteristikama značajno umanjena pristranost liječnika koja bi mogla utjecati na rezultate istraživanja. Jedna od prednosti RCT-a jest i mogućnost uključivanja velikog broja ispitanika. Randomizirane kliničke studije često se organiziraju u obliku multicentričnih dvostruko slijepih istraživanja, što znači da se istovremeno u različitim kliničkim centrima diljem svijeta provode jednaka istraživanja ${ }^{12}$. Samim time uvelike raste i uzorak, što također pridonosi većoj pouzdanosti rezultata. Bez obzira na velik broj prednosti, postoje i određeni nedostatci randomiziranih kliničkih istraživanja. Prvi od njih jest etičko pitanje opravdanosti izvođenja pojedinih eksperimenata na ljudima ${ }^{13}$. Jedan od primjera takve vrste istraživanja bilo je istraživanje na trudnicama o utjecaju vitaminskih suplemenata na razvoj defekata zatvaranja neuralne cijevi kod novorođenčadi ${ }^{14}$. lako su neka ranija istraživanja dokazala da folna kiselina uvelike smanjuje njihovu incidenciju, postojale su značajne poteškoće u regrutaciji dobrovoljnih ispitanika, jer se većina trudnica nije htjela izložiti riziku. Postavljalo se pitanje je li opravdano trudnice izlagati mogućem riziku u svrhu razvoja medicinske znanosti. Isto tako, za određena vrsta istraživanja nemoguće je provesti randomizaciju (npr. utjecaj pušenja na razvoj kar- 
cinoma pluća), jer bi na taj način ispitanici bili primorani svjesno ugroziti vlastito zdravlje. Još jedna negativna strana jest cijena samog istraživanja. Kako je već ranije opisano, randomizirana klinička istraživanja su dugogodišnja istraživanja, koja su često i multicentrična, što zahtijeva velika financijska ulaganja. Upravo su financije čest razlog zbog kojeg se određena randomizirana klinička istraživanja nikada ne ostvare. Jedna od negativnih strana njihove cijene jest da ih često sponzoriraju interesne skupine, odnosno farmaceutske

Adekvatna informiranost pacijenata ključna je za daljnji napredak kliničkih istraživanja.

kompanije. Farmaceutske kompanije na taj način stvaraju jedan oblik pristranosti kod istraživača te mogu rezultirati nevjerodostojnim rezultatima istraživanja, koji na koncu najviše štete pacijenti$\mathrm{ma}^{15}$. Posljednja, ali sigurno ne i najmanje važna negativna strana jest nedovoljno dobra informiranost pacijenata. Kako bi se istraživanje uopće moglo ostvariti potrebno je skupiti reprezentativan broj ispitanika. Ispitanici su dobrovoljci, kojima njihovi liječnici mogu ponuditi priliku sudjelovanja u istraživanju. No velik problem krije se $u$ tome što pacijenti nisu upoznati s pojmom randomiziranih kliničkih istraživanja te često nisu niti svjesni koliko su rezultati istraživanja važni za medicinsku praksu, ali ponajviše i za njih same. Istraživanje koje je provedeno 2008. godine u Škotskoj otkrilo je kako je samo 14,8 \% ispitanika iz opće populacije upoznato s terminom randomiziranih kliničkih istraživanja, a među njima bi $31,3 \%$ htjelo sudjelovati u istraživanjima ${ }^{16}$. Upravo u boljoj promidžbi važnosti randomiziranih kliničkih istraživanja među općom populacijom nalazi se ključ njihova daljnja unaprjeđenja.

\section{ZAKLJUČAK}

Randomizirana klinička istraživanja uvelike su zaslužna za ubrzan razvoj medicine posljednjih nekoliko desetljeća, a istovremeno su i temelj za njezin daljnji razvoj. Glavna zadaća randomiziranih kliničkih istraživanja jest promocija zdravlja, pomoću razumijevanja prednosti i nedostataka određenih terapijskih postupaka. Olakšavaju posao liječnici- ma u svakodnevnom kliničkom radu, a istodobno pomažu pacijentima, osiguravajući im najkvalitetniji mogući oblik zdravstvene zaštite. Isto tako treba reći da usprkos svim svojim prednostima, još uvijek postoji mogućnost njihova daljnjeg razvoja. Taj napredak se ponajprije odnosi na bolju informiranost javnosti o važnosti provođenja randomiziranih kliničkih istraživanja, što je prvenstveno zadaća liječnika, ali i masovnih medija. Porastom udjela broja ispitanika rezultati kliničkih istraživanja postat će objektivniji i vjerodostojniji, a kvaliteta liječenja bolja. Možda i najbolji odgovor na pitanje koliko su randomizirana klinička istraživanja važna dao je Archibald Cochrane, osnivač Cochrane kolaboracije, koji je jednom prilikom izjavio: "You should randomize till it hurts"1.

Izjava o sukobu interesa: autori izjavljuju da ne postoji sukob interesa.

\section{LITERATURA}

1. Shah $\mathrm{MH}$, Chung $\mathrm{CK}$. Archie Cochrane and his vision for evidence-based medicine. Plast Reconstr Surg 2009; 124:982-8.

2. Kabisch M, Ruckes C, Seibert-Grafe M, Blettner M. Randomized Controlled Trials. Dtsch Arztebl Int 2011;108: 663-8.

3. Sadeghi-Bazargani $H$, Sedghipour MR. Setting the objectives and hypotheses in randomized clinical trials: notices for clinicians and pharmacologists. Int J Pharmacol 2012;8:475-82.

4. Jadad AR, Enkin MW. Randomized Controlled Trials: The Basics. In: Jadad AR, Enkin MW (eds). Randomized Controlled Trials: Questions, Answers, and Musings. Second Edition. Oxford, UK: Blackwell Publishing Ltd, 2007.

5. Francetić I. Klinička ispitivanja i medicina osnovana na dokazima. In: Vrhovac B, Jakšić B, Reiner Ž, Vucelić B (eds). Interna medicina. Četvrto promijenjeno i dopunjeno izdanje. Zagreb: Naklada Ljevak, 2008.

6. Sibbald B, Roland M. Understanding controlled trials: why are randomised controlled trials important? BMJ 1998;316:201.

7. Stanley K. Design of randomized clinical trials. Circulation 2007;115:1164-9.

8. Kabisch M, Ruckes C, Seibert-Grafe M, Blettner M. Randomized controlled trials: part 17 of a series on evaluation of scientific publications. Dtsch Arztebl Int 2011; 108:663-8.

9. guides.osu.edu [Internet]. Columbus, Ohio: The Ohio State University. University libraries [cited 10 May 2017]. Available from: http://guides.osu.edu/pharmacy/EBM.

10. Kennedy LH. The importance of randomized clinical trials and evidence-based medicine: a clinician's perspective. Clin Cardiol 1999;22:6-12.

11. Echt DS, Liebson PR, Mitchell LB, Peters RW, Obias-Manno $\mathrm{D}$, Barker $\mathrm{AH}$ et al. Mortality and morbidity in pati- 
ents receiving encainide, flecainide, or placebo. The Cardiac Arrhythmia Suppression Trial. N Engl J Med 1991;324:781-8

12. Stang A. Randomized controlled trials - an indispensible part of clinical research. Dtsch Arztebl Int 2011; 108:661-2.

13. World Medical Association. World Medical Association Declaration of Helsinki: ethical principles for medical research involving human subjects. JAMA 2013;310: 2191-4.
14. Smithells RW, Shepherd S, Schorah CJ, Seller MJ, Nevin NC, Harris R et al. Possible prevention of neural tube defects by periconceptional vitamin supplementation. Lancet 1980;1:339-40.

15. Dreyfuss D. Beyond randomized, controlled trials. Curr Opin Crit Care 2004;10:574-8.

16. Mackenzie IS, Wei L, Rutherford D, Findlay EA, Saywood $\mathrm{W}$, Campbell MK et al. Promoting public awareness of randomised clinical trials using the media: the 'Get Randomised' campaign. Br J Clin Pharmacol 2010;69:128-35. 